\title{
Prediction formulas of maximum scour depth and impact location of a local scour hole below a chute spillway with a flip bucket
}

\author{
S. Heng ${ }^{1}$, T. Tingsanchali ${ }^{2,3} \&$ T. Suetsugi ${ }^{1}$ \\ ${ }^{1}$ Interdisciplinary Graduate School of Medicine and Engineering, \\ University of Yamanashi, Japan \\ ${ }^{2}$ Nakhon Pathom Rajabhat University, Thailand \\ ${ }^{3}$ Asian Institute of Technology, Thailand
}

\begin{abstract}
The objectives of this research are to (1) analyze and select the most appropriate existing formulas for predicting maximum scour depth $\left(D_{S}\right)$ and impact location $\left(L_{S}\right)$ of a local scour hole in the plunge pool below a chute spillway with flip bucket, and (2) establish a new $D_{S}$ method functional with the easily available data, discharge $(Q)$ and tailwater depth, based on experimental results. The experiment was conducted with the Nam Ngum 3 spillway physical model. Each $D_{S}$ and $L_{S}$ formula has its own limitation and therefore does not perform well with different ranges of $Q$. For $D_{S}$ prediction, the combined method of Mason-B (for low $Q$ ), Taraimovich (for medium $Q$ ) and Mason-A (for high $Q$ ) was found to provide high accurate results with Nash-Sutcliffe Efficiency (NSE) of 0.99, root mean square error (RMSE) of $1.84 \mathrm{~m}$ and mean absolute percentage error (MAPE) of $3.86 \%$. Similarly for the case of $L_{S}$, the combined method of Kawakami-Taraimovich (for low and high $Q$ ) and Elevatorski-Taraimovich (for medium $Q$ ) is the most ideal technique. By using dimensionless analysis, the new $D_{S}$ formula was established and its statistical performance indicated by NSE, RMSE and MAPE is $1.00,0.97 \mathrm{~m}$ and $2.35 \%$, respectively. The coupled approach of Mason-B, Taraimovich and Mason-A is recommended when there are sufficient input data because many factors are associated and thus high accurate results are expected. However, in data-constraint situations, the new $D_{S}$ formula would be more feasible.

Keywords: maximum scour depth, impact location, local scour hole, plunge pool, chute spillway with flip bucket, numerical method, physical model.
\end{abstract}




\section{Introduction}

Rapid population growth has led to high demand of electricity and water for consumptive use. Huge amount of water is of course required for food production especially in agricultural sector. Consequently, many dams have been developed and planned for regulating this vital resource in order to supply such non-stop increasing need. According to ICOLD [1], the number of world large dams reached 37,641. The world tenth largest Mekong River is very rich in hydropower resource and 136 dams (26 existing, 14 under construction and 96 planned) would be developed to exploit this vital energy (MRC [2]). Large dams are generally constructed with overflow spillways. The overflow from such infrastructures may scour the structure foundation in case energy of the water jets exceeds the strength of existing riverbed or is not fully dissipated in the plunge pool [3-5]. Long term of scour process may endanger the stability of the dam/spillway and also downstream river channel $[4,6]$.

The concrete protection blocks at the foundation of Keban dam (Turkey) were demolished by scouring at low flow operation (Yildiz and Uzucek [7]). In the plunge pool of Tarbela dam (Pakistan), scour hole developed toward the right bank (Yildiz and Uzucek [7]). In 1982, high discharge water jets released from the spillway caused a remarkable scour hole of about $80 \mathrm{~m}$ deep in the plunge pool of Kariba dam in Africa (Annandale [6]). In China, a scour depth of just over $100 \mathrm{~m}$ deep was predicted to occur at downstream of the Three Gorges dam (Liu [4]). Based on these facts and figures, local scour events at the downstream dam foundation should be given more attention in order to ensure safety of the structures. Prediction of plunge pool scour hole is very difficult because scour process varies with many factors including hydraulic, morphologic and hydrologic conditions, as well as characteristics of the structure and flow regulation rule (Annandale [6]). In this context, the most reliable method is the use of physical model (Heng et al. [5]). However, this technique is costly and time consuming.

Due to complex mechanism of scouring and the said disadvantages of physical modeling tool, numerical approaches are of interest. Based on extensive literature review, large amount of numerical methods has been initiated and majority of them is empirically based and focuses on maximum scour depth $\left(D_{S}\right)$ prediction. Moreover, only few methods were developed for estimating impact location $\left(L_{S}\right)$. It is understood that those methods cannot be applied definitely for detailed design purposes but they are useful during preliminary/feasibility study and design of plunge pool pit in the physical model while available data are generally so limited. For large structure, the scour hole prediction using physical model is generally required and important for its confident and reliable information for detailed design. Moreover, such data-driven methods are normally developed using combined data of different conditions. Field observed data of $D_{S}$ and $L_{S}$ are not often available. As a consequence, some methods are established using experimental data.

Hence, the main objectives of this research are to (1) analyze and select the most appropriate existing formulas for predicting $D_{S}$ and $L_{S}$ of local scour hole in 
the plunge pool below a chute spillway with flip bucket, and (2) establish a new $D_{S}$ method functional with the easily available data, discharge and tailwater depth, based on experimental results. Since large amount of existing methods is taken into account, their in-depth background is not given and only the main equation is presented. $D_{S}$ is the head difference between the tailwater surface and scour hole bottom. $L_{S}$ is the distance measured horizontally from the bucket lip of spillway to the location of $D_{S}$.

\section{Materials and methods}

In this study, 28 and 3 existing methods were applied for estimating $D_{S}$ and $L_{S}$, respectively. Among these formulas, the most appropriate one was selected based on their good performance which is strongly consistent with the experimental results. The physical model of Nam Ngum 3 spillway was used for conducting the experiment. The results obtained from the experiment were also considered for development of the new $D_{S}$ method using dimensionless analysis.

\subsection{Experiment}

The experiment was carried out with Nam Ngum 3 spillway physical model constructed in the hydraulic laboratory of Asian Institute of Technology, Thailand. At an undistorted geometric scale of 1:75, the model body composes of three main parts. (1) The upstream boundary covers a distance of about $300 \mathrm{~m}$ from the dam axis and a total width of approximately $400 \mathrm{~m}$. The natural topography of reservoir behind the dam wall was also reproduced in the model. (2) The control structure consists of dam body, inlet piers, radial gates and chute spillway with flip bucket. (3) The downstream boundary was reproduced following the natural flood valley of the river over a length of around $600 \mathrm{~m}$ from the spillway flip bucket. The plunge pool pit was built hollowly with $3.0 \mathrm{~m}$ long, $1.2 \mathrm{~m}$ wide and $1.0 \mathrm{~m}$ deep (model dimension). A flap gate was installed at downstream end for adjusting the tailwater depth determined by eqn. (1). Layout of the spillway physical model is illustrated in fig. 1 .

$$
h=0.17851 Q^{0.523149} .
$$

where $h(\mathrm{~m})$ is the tailwater depth and $Q\left(\mathrm{~m}^{3} / \mathrm{s}\right)$ is the discharge.

Following the spillway operation rule, the experiment of scour hole reproduction was tested with steady flows ranging from 1,000 to $8,182 \mathrm{~m}^{3} / \mathrm{s}$. There are in total 13 tests which are corresponding to 13 different $Q$. For each test, the pit was filled with cohesive movable riverbed material which is the mixture of Sand (40): Cement (1): Water (5) and the surface elevation was also set according to the natural topography. The testing period lasts until the scour process is not further observed, around one hour (model dimension). More details about selection of the movable riverbed material, testing period and design of physical model, can be found in Heng et al. [5]. 


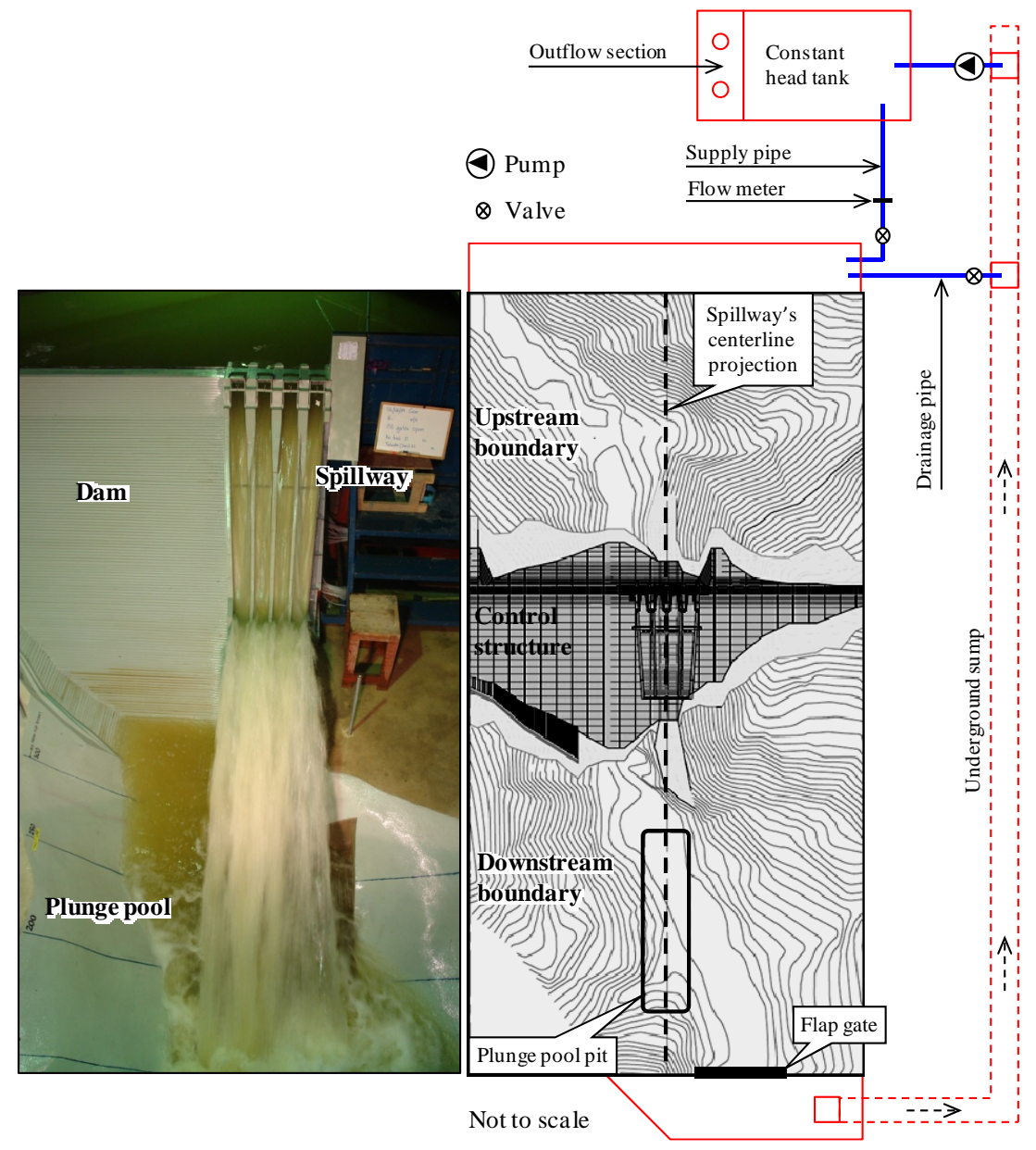

Figure 1: $\quad$ Physical model (left) and layout plan (right).

\subsection{Existing formulas of maximum scour depth $\left(D_{S}\right)$}

All 28 prediction formulas of $D_{S}(1932-2007)$ are summarized as below. Fig. 2 defines all the parameters used in these methods. Eighteen (18) formulas having a common form as shown in eqn. (2) are tabulated in table 1 . The other 10 formulas (1939-2005) are presented in table 2.

$$
D_{S}=k \frac{q^{x} H^{y}}{d^{z}} \text {. }
$$

where $q\left(\mathrm{~m}^{3} / \mathrm{s} / \mathrm{m}\right)$ is the discharge per unit width, $H(\mathrm{~m})$ is the head drop between reservoir water surface and tailwater surface, $d(\mathrm{~m})$ is the characteristic particle size of bed material, $k$ is the constant, and $x, y$ and $z$ are the exponent coefficient of $q, H$ and $d$, respectively. 
Reservoir water surface

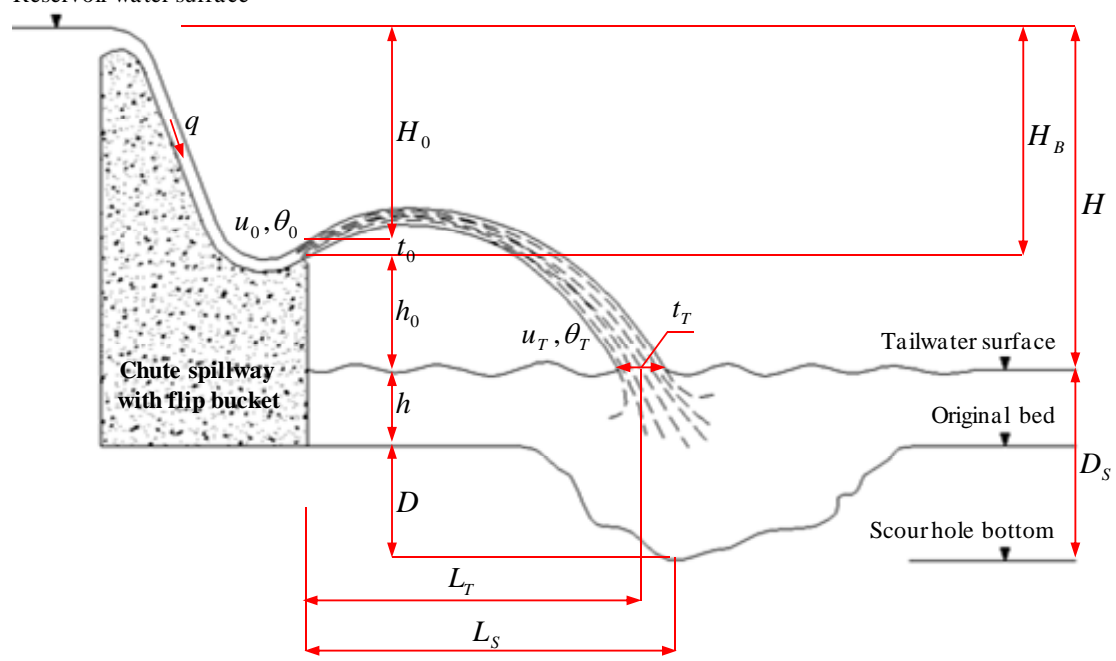

Figure 2: $\quad$ Definition sketch of parameters used in $D_{S}$ and $L_{S}$ formulas.

Table 1: $\quad$ List of 18 common formulas represented by eqn. (2).

\begin{tabular}{|c|l|c|c|c|c|c|c|}
\hline No. & Name of formula & Year & $k$ & $x$ & $y$ & $z$ & $d$ \\
\hline 1 & Schoklitsch & 1932 & 0.521 & 0.57 & 0.20 & 0.32 & $d_{90}$ \\
\hline 2 & Veronese-A & 1937 & 0.202 & 0.54 & 0.225 & 0.42 & $d_{m}$ \\
\hline 3 & Veronese-B & 1937 & 1.90 & 0.54 & 0.225 & 0 & - \\
\hline 4 & Eggenburger & 1944 & 1.44 & 0.60 & 0.50 & 0.40 & $d_{90}$ \\
\hline 5 & Hartung & 1959 & 1.40 & 0.64 & 0.36 & 0.32 & $d_{85}$ \\
\hline 6 & Franke & 1960 & 1.13 & 0.67 & 0.50 & 0.50 & $d_{90}$ \\
\hline 7 & Damle-A & 1966 & 0.652 & 0.50 & 0.50 & 0 & - \\
\hline 8 & Damle-B & 1966 & 0.543 & 0.50 & 0.50 & 0 & - \\
\hline 9 & Damle-C & 1966 & 0.362 & 0.50 & 0.50 & 0 & - \\
\hline 10 & Chee and Padiyar & 1969 & 2.126 & 0.67 & 0.18 & 0.063 & $d_{m}$ \\
\hline 11 & Bisaz and Tschopp & 1972 & 2.76 & 0.50 & 0.25 & 1.00 & $d_{90}$ \\
\hline 12 & Chee and Kung & 1974 & 1.663 & 0.60 & 0.20 & 0.10 & $d_{m}$ \\
\hline 13 & Martins-B & 1975 & 1.50 & 0.60 & 0.10 & 0 & - \\
\hline 14 & Taraimovich & 1978 & 0.633 & 0.67 & 0.25 & 0 & - \\
\hline 15 & Machado & 1980 & 1.35 & 0.50 & 0.3145 & 0.0645 & $d_{90}$ \\
\hline 16 & SOFRELEC & 1980 & 2.30 & 0.60 & 0.10 & 0 & - \\
\hline 17 & INCYTH & 1981 & 1.413 & 0.50 & 0.25 & 0 & - \\
\hline 18 & Suppasri & 2007 & 0.15 & 0.38 & 0.75 & 0 & - \\
\hline
\end{tabular}

Source: modified from $[8,9]$. 
Table 2: $\quad$ List of 10 formulas having different form from eqn. (2).

\begin{tabular}{|c|c|c|c|c|}
\hline No. & $\begin{array}{l}\text { Name of } \\
\text { formula }\end{array}$ & Year & Equation & Source \\
\hline 19 & Jaeger & 1939 & $D_{S}=0.6 q^{0.5} H^{0.25}\left(h / d_{m}\right)^{0.333}$. & \multirow{6}{*}{$\begin{array}{l}\text { Mason and } \\
\text { Arumugam } \\
{[8]}\end{array}$} \\
\hline 20 & Mikhalev & 1960 & $D_{S}=\frac{1.804 q \sin \theta_{T}}{1-0.215 \cot \theta_{T}}\left(\frac{1}{d_{90}^{0.33} h^{0.50}}-\frac{1.126}{H}\right)$ & \\
\hline 21 & Rubinstein & 1965 & $D_{S}=h+0.19\left(\frac{H+h}{d_{90}}\right)^{0.75}\left(\frac{q^{1.20}}{H^{0.47} h^{0.33}}\right)$ & \\
\hline 22 & Mirskhulava & 1967 & $D_{S}=\left(\frac{0.97}{\sqrt{d_{90}}}-\frac{1.35}{\sqrt{H}}\right) \frac{q \sin \theta_{T}}{1-0.175 \cot \theta_{T}}+0.25 h$ & \\
\hline 23 & Martins-A & 1973 & $\left\{\begin{array}{l}D_{S}=0.14 N-0.73 \frac{h^{2}}{N}+1.7 h \\
N=\left(Q^{3} H^{1.5} / d_{m}^{2}\right)^{1 / 7}\end{array}\right.$ & \\
\hline 24 & Mason-A & 1985 & $D_{S}=3.27 \frac{q^{0.60} H^{0.05} h^{0.15}}{g^{0.30} d^{0.10}}$ & \\
\hline 25 & Mason-B & 1989 & $D_{S}=3.39 \frac{q^{0.60}(1+\beta)^{0.30} h^{0.16}}{g^{0.30} d^{0.06}}$ & Mason [10] \\
\hline 26 & \begin{tabular}{|l|} 
Modified \\
Veronese
\end{tabular} & 1994 & $D_{S}=1.90 h^{0.225} q^{0.54} \sin \theta_{T}$. & $\begin{array}{l}\text { Yildiz and } \\
\text { Uzucek [7] }\end{array}$ \\
\hline 27 & Hoffmans & 1998 & $D_{S}=c_{2 v} \sqrt{\frac{q u_{T} \sin \theta_{T}}{g}}$ & $\begin{array}{l}\text { Hoffmans } \\
{[11]}\end{array}$ \\
\hline 28 & Liu & 2005 & $\left\{\begin{array}{l}D_{S}=\sqrt{h^{2}+k_{t}^{2} \frac{q \sqrt{H}}{\sqrt{g}}} . \\
D_{S}=t_{T} \sin \theta_{T}\left(\frac{k_{e}^{2}}{k_{t}^{2}}\right)^{1 / m} .\end{array}\right.$ & Liu [4] \\
\hline $\begin{array}{l}\text { : } \\
\text { : } \\
\text {. } \\
\text {. } \\
\text { : } \\
\text { : } \\
\text { : } \\
\text { : }\end{array}$ & $\begin{array}{l}d_{m}(\mathrm{~m}) \text { is the } \mathrm{I} \\
\theta_{T}\left({ }^{\circ}\right) \text { is the je } \\
d_{90}(\mathrm{~m}) \text { is the } \\
g\left(9.81 \mathrm{~m} / \mathrm{s}^{2}\right) \\
\beta \text { is the ratio } \mathrm{x} \\
u_{T}(\mathrm{~m} / \mathrm{s}) \text { is the } \\
c_{2 v} \text { is the coef } \\
k_{t} \text { is the hydra } \\
k_{e} \text { is the scour } \\
t_{T}(\mathrm{~m}) \text { is the je } \\
m \text { is the expol }\end{array}$ & $\begin{array}{l}\text { ize of b } \\
\text { s the gr } \\
\text { f air to } \\
\text { jet imp } \\
\text { icient } r \\
\text { lic fact } \\
\text { coeffici } \\
t \text { thickn }\end{array}$ & $\begin{array}{l}\text { rticle size of bed material. } \\
\text { angle to tailwater surface. } \\
\text { ed material of which } 90 \% \text { by weight is smaller. } \\
\text { avitational acceleration. } \\
\text { water. } \\
\text { act velocity at the tailwater surface. } \\
\text { lated to } d_{90} \text {. } \\
\text { or (impact of water jet and erosion resisting behavior of bec } \\
\text { lent of bedrock. } \\
\text { ess at the point of impingement. } \\
\text { fficient connected to the depth of water cushion. }\end{array}$ & drock). \\
\hline
\end{tabular}




\subsection{Existing formulas of impact location $\left(L_{S}\right)$}

Three different methods: Elevatorski [12], Kawakami [13] and USBR [14] were applied for non-submerged jet (from bucket lip to point of impingement). It means that these three methods can estimate only the horizontal distance $\left(L_{T}\right)$ between the bucket lip and point of impingement on the tailwater surface. In case of submerged jet (from tailwater surface to scour hole bottom), the concept of Taraimovich [15] was used. It means that Taraimovich [15] provides the difference between $L_{S}$ and $L_{T}$. In short, $L_{S}$ was estimated using the coupled method of submerged and non-submerged jet. The coupled formula of Elevatorski-Taraimovich, Kawakami-Taraimovich and USBR-Taraimovich is respectively represented by eqn. (3), (4) and (5).

$$
L_{S}=1.9 H_{B} \sin 2 \theta_{0}+D_{S} \tan \left(90-\theta_{T}\right) \text {. }
$$

where $H_{B}(\mathrm{~m})$ is the head difference between reservoir water surface and bucket lip and $\theta_{0}\left(^{\circ}\right)$ is the angle of flip bucket or water jet at the end of flip bucket.

$$
L_{S}=\frac{1}{g k_{0}^{2}} \ln \left(1+2 k_{0} u_{0 X} \alpha\right)+\left(h_{0}+D_{S}\right) \tan \left(90-\theta_{T}\right) .
$$

where $k_{0}$ is the coefficient related to air resistance, $\alpha=\tan ^{-1}\left(k_{0} \times u_{0 Y}\right), u_{0 X}(\mathrm{~m} / \mathrm{s})$ and $u_{0 Y}(\mathrm{~m} / \mathrm{s})$ are respectively the horizontal and vertical component of flow velocity at the end of flip bucket, $h_{0}(\mathrm{~m})$ is the head different between bucket lip and tailwater surface.

$$
h_{0}+D_{S}=\frac{L_{S}}{0.9} \tan \theta_{0}-\frac{\left(L_{S} / 0.9\right)^{2}}{4 K_{R}\left(t_{0}+\varphi H_{0}\right) \cos ^{2} \theta_{0}} .
$$

where $K_{R}$ is the reduction coefficient due to air resistance, $\varphi$ is the coefficient of spillway head loss, $t_{0}(\mathrm{~m})$ is the jet thickness at the end of flip bucket and $H_{0}=$ $H_{B}-t_{0}$.

\subsection{Evaluation and comparison of $D_{S}$ and $L_{S}$ formulas}

The efficiency of each $D_{S}$ and $L_{S}$ method was measured by Nash-Sutcliffe Efficiency (NSE) which is the most widely used goodness-of-fit indicator. With NSE greater than 0.50, the efficiency of the applied formula is judged satisfactory (Moriasi et al. [16]). Together with NSE, root mean square error (RMSE) and mean absolute percentage error (MAPE) were employed for comparing the performance of each method. The most ideal formula should contain the highest value of NSE and the lowest value of RMSE and MAPE. NSE, $R M S E$ and MAPE were calculated using eqn. (6), (7) and (8), respectively.

$$
N S E=1-\frac{\sum(X-Y)^{2}}{\sum\left(X-X_{a v g}\right)^{2}} .
$$




$$
\begin{aligned}
& \text { RMSE }=\sqrt{\frac{1}{n} \sum(X-Y)^{2}} . \\
& M A P E=100 \frac{1}{n} \sum\left|\frac{X-Y}{X}\right| .
\end{aligned}
$$

where $X$ is the experimental $D_{S}$ or $L_{S}$ with the mean value $X_{\text {avg }}, Y$ is the estimated $D_{S}$ or $L_{S}$ of each formula and $n$ is the sample size or number of tests.

\section{Results and discussion}

\subsection{Experimental results}

The experimental $D_{S}$ and $L_{S}$ resulted from each test are graphically shown in fig. 3. From minimum to maximum $Q, D_{S}$ varies from about 18 to $94 \mathrm{~m}$ while $L_{S}$ varies from 173 to $252 \mathrm{~m}$. It can be seen that the scour hole is deeper and the impact location is further with higher $Q$. In addition, $D_{S}$ occurs on the right side of the spillway's centerline projection about $3.75 \mathrm{~m}$ for $Q$ equal to $1,000,1,500$ and $1,750 \mathrm{~m}^{3} / \mathrm{s}$ because of the high ground level of the left bank reflecting the jet impingement to the opposite site. In case of $Q$ equal to 2,000, 2,500 and 3,000 $\mathrm{m}^{3} / \mathrm{s}$, location of $D_{S}$ is on the spillway's centerline projection. For higher $Q$ from 3,500 to $8,182 \mathrm{~m}^{3} / \mathrm{s}$, location of $D_{S}$ changes subsequently toward the left bank because the water jets impinge on the right bank reflecting lateral hydraulic forces to the left side.

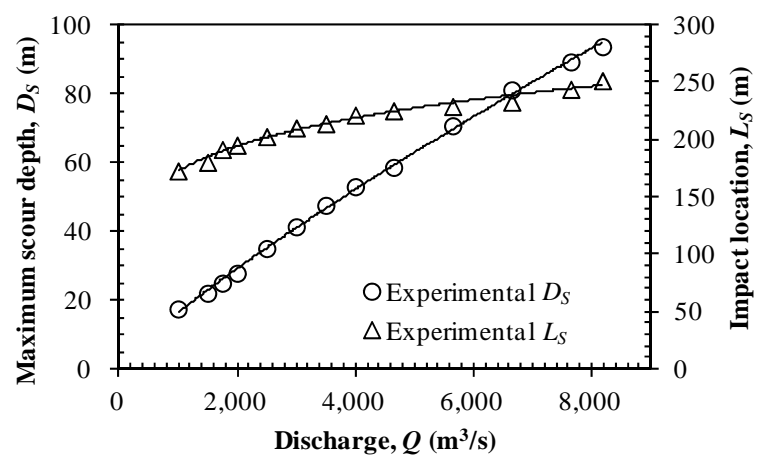

Figure 3: $\quad$ Experimental results.

\subsection{Comparison of $D_{S}$ formulas}

Table 3 presents the statistical performance of all 28 formulas used for estimating $D_{S}$ in this particular condition. The efficiency of each method indicated by NSE varies from -42.11 (Franke) to 0.99 (Mirskhulava). Only 13 formulas provide satisfactory result with NSE value greater than 0.50. RMSE value ranges from 3.07 (Mirskhulava) to $164.81 \mathrm{~m}$ (Franke). There are only five 
methods having RMSE value less than $10 \mathrm{~m}$. In term of MAPE, some formulas contain very high error (MAPE > 100\%). Only Taraimovich and Mirskhulava have MAPE value less than $10 \%$. Based on these statistical indices (NSE, RMSE and MAPE), Mirskhulava is the most ideal formula in predicting $D_{S}$. It has the highest value of NSE (0.99) and the lowest value of RMSE (3.07 m) and MAPE (7.86\%). Taraimovich is the second ideal method with NSE, RMSE and MAPE correspondingly equal to $0.95,5.75 \mathrm{~m}$ and $9.93 \%$.

Table 3: $\quad$ Performance of $D_{S}$ formulas indicated by NSE, RMSE and MAPE.

\begin{tabular}{|c|c|c|c|c|}
\hline No. & Name of formula & NSE & RMSE (m) & MAPE (\%) \\
\hline 1 & Schoklitsch & -1.74 & 41.58 & 68.78 \\
\hline 2 & Veronese-A & -3.21 & 51.53 & 88.94 \\
\hline 3 & Veronese-B & 0.36 & 20.06 & 52.88 \\
\hline 4 & Eggenburger & -41.65 & 163.94 & 337.80 \\
\hline 5 & Hartung & -8.67 & 78.07 & 162.03 \\
\hline 6 & Franke & -42.11 & 164.81 & 324.68 \\
\hline 7 & Damle-A & -0.86 & 34.22 & 85.98 \\
\hline 8 & Damle-B & 0.35 & 20.30 & 54.89 \\
\hline 9 & Damle-C & 0.79 & 11.42 & 19.51 \\
\hline 10 & Chee and Padiyar & -4.74 & 60.15 & 123.93 \\
\hline 11 & Bisaz and Tschopp & 0.49 & 17.91 & 21.01 \\
\hline 12 & Chee and Kung & 0.65 & 14.75 & 38.76 \\
\hline 13 & Martins-B & 0.35 & 20.28 & 25.41 \\
\hline 14 & Taraimovich & 0.95 & 5.75 & 9.93 \\
\hline 15 & Machado & 0.71 & 13.51 & 37.68 \\
\hline 16 & SOFRELEC & 0.87 & 8.94 & 24.72 \\
\hline 17 & INCYTH & 0.84 & 10.09 & 20.60 \\
\hline 18 & Suppasri & 0.19 & 22.62 & 27.95 \\
\hline 19 & Jaegae & 0.56 & 16.74 & 22.38 \\
\hline 20 & Mikhalev & 0.17 & 22.84 & 36.03 \\
\hline 21 & Rubinstein & 0.79 & 11.48 & 14.50 \\
\hline 22 & Mirskhulava & 0.99 & 3.07 & 7.86 \\
\hline 23 & Martins-A & 0.01 & 24.93 & 30.33 \\
\hline 24 & Mason-A & 0.95 & 5.37 & 14.63 \\
\hline 25 & Mason-B & 0.69 & 13.90 & 17.09 \\
\hline 26 & Modified Veronese & 0.00 & 25.12 & 37.24 \\
\hline 27 & Hoffmans & 0.85 & 9.84 & 26.82 \\
\hline 28 & Liu & 0.69 & 13.87 & 24.93 \\
\hline
\end{tabular}

Scatter plot of the experimental versus estimated $D_{S}$ is depicted in fig. 4 . About $45 \%$ of the scattering points locate below the ideal fit line indicating underestimations and the remaining 55\% are above the ideal fit line showing overestimations. It is also apparent that some formulas perform somewhat satisfactorily at low $Q$ but very badly at medium and high $Q$, e.g. Martins-A and Martins-B. It is vice versa for some other methods. Therefore, $Q$ series was 
divided into three ranges: low $\left(1,000-2,500 \mathrm{~m}^{3} / \mathrm{s}\right)$, medium $\left(3,000-4,647 \mathrm{~m}^{3} / \mathrm{s}\right)$ and high (5,647-8,182 $\left.\mathrm{m}^{3} / \mathrm{s}\right)$. From fig. 4, it is observed that Mason-B performs well at low $Q$, Taraimovich at medium $Q$ and Mason-A at high $Q$. By combining these three formulas together, the prediction accuracy is significantly improved in comparing with the most ideal method, Mirskhulava. The combined formula has NSE, RMSE and MAPE value equal to 0.99, $1.84 \mathrm{~m}$ and 3.86\%, respectively. It is superior for less $40 \%$ of $R M S E$ and $51 \%$ of MAPE. In term of NSE, the performance of both techniques is comparable.

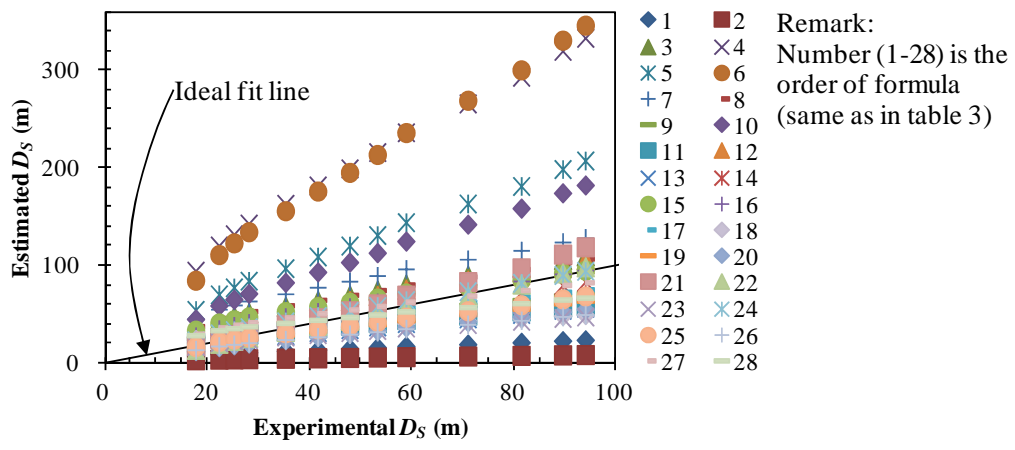

Figure 4: $\quad$ Scatter plot of the experimental versus estimated $D_{S}$.

\subsection{Comparison of $L_{S}$ formulas}

As shown in table 4, only Kawakami-Taraimovich formula yields acceptable result with NSE (=0.81) greater than 0.50 . This method also performs better than others in term of RMSE (= $9.92 \mathrm{~m})$ and MAPE (3.86\%). Therefore, KawakamiTaraimovich is considered as the most ideal formula in predicting $L_{S}$. Fig. 5 shows the scatter plot of the experimental versus estimated $L_{S}$. Majority of the scattering points (72\%) locates above the ideal fit line indicating overestimations. It is also observed that the performance of ElevatorskiTaraimovich is rather better than that of the ideal method at medium Q. By combining Kawakami-Taraimovich (for low and high $Q$ ) and ElevatorskiTaraimovich (for medium $Q$ ) together, the prediction result is relatively better with NSE, RMSE and MAPE respectively equal to $0.87,8.23 \mathrm{~m}$ and $3.22 \%$. It is superior to Kawakami-Taraimovich alone for larger NSE 7\%, less RMSE 17\% and less MAPE $16 \%$.

Table 4: $\quad$ Performance of $L_{S}$ formulas indicated by NSE, RMSE and MAPE.

\begin{tabular}{|c|l|c|c|c|}
\hline No. & Name of formula & NSE & RMSE (m) & MAPE (\%) \\
\hline 1 & Elevatorski-Taraimovich & 0.33 & 18.91 & 7.20 \\
\hline 2 & Kawakami-Taraimovich & 0.81 & 9.92 & 3.86 \\
\hline 3 & USBR-Taraimovich & -1.74 & 38.13 & 17.80 \\
\hline
\end{tabular}




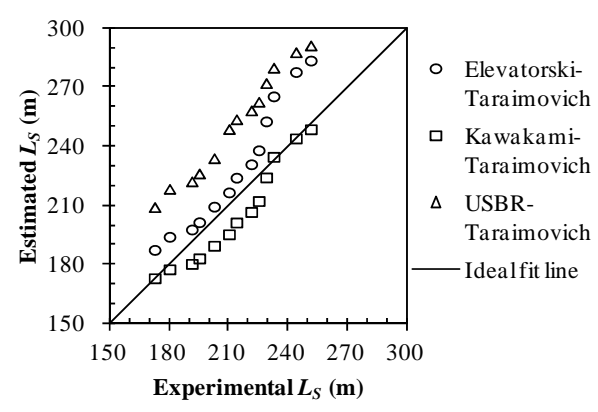

Figure 5: $\quad$ Scatter plot of the experimental versus estimated $L_{S}$.

\subsection{Development of new $D_{S}$ formula}

The purpose of developing the new formula is to make $D_{S}$ predictable with the easily available data, $Q$ and $h$. Information on these two variables is generally determined during project planning for rating curve generation as presented in eqn. (1). In addition, $Q$ is associated in all existing formulas and this reveals that it is the most important factor governing $D_{S}$. The tailwater depth $(h)$ plays an important role in dissipating energy of the falling jets. The gravitational acceleration $(g)$ was also taken into account since this is the case of free falling jet. Based on dimensionless analysis, general form of the new $D_{S}$ formula is represented by eqn. (9). After conducting the regression analysis and afterward simplification, specific equation of the new $D_{S}$ method is shown in eqn. (10). Its statistical performance indicated by NSE, RMSE and MAPE is $1.00,0.97 \mathrm{~m}$ and $2.35 \%$, correspondingly.

$$
\begin{gathered}
\frac{D_{S}}{h}=a\left(\frac{q^{2}}{g h^{3}}\right)^{b} \\
D_{S}=7.4834 \frac{q^{1.4652}}{g^{0.7326} h^{1.1978}}
\end{gathered}
$$

\section{Conclusions}

Twenty-eight (28) and three (3) existing formulas were applied respectively to estimate $D_{S}$ and $L_{S}$, and their results were compared with the experimental ones. Although the formula of Mirskhulava alone performs well in predicting $D_{S}$, the combination of Mason-B (for low Q), Taraimovich (for medium Q) and MasonA (for high $Q$ ) provides much better results. Each individual method has its own limitation and therefore does not work well with different ranges of $Q$. In case of $L_{S}$ prediction, similar situation is observed. The combination of KawakamiTaraimovich (for low and high $Q$ ) and Elevatorski-Taraimovich (for medium $Q$ ) yields more accurate results than using Kawakami-Taraimovich alone. Based on the experimental outputs, a new $D_{S}$ method was established and it is functional with the easily available data $(Q$ and $h)$. For $D_{S}$ prediction, the combined method 
of Mason-B, Taraimovich and Mason-A is recommended when there are sufficient input data. It is expected to provide more accurate results than the proposed formula because many factors (variables) are associated. However, in data-constraint situation, the new $D_{S}$ formula would be more feasible.

\section{References}

[1] International Commission on Large Dams (ICOLD). The World Register of Dams, http://www.icold-cigb.net/GB/World_register/general_synthesis.asp.

[2] Mekong River Commission (MRC), Planning atlas of the Lower Mekong River Basin, MRC: Phnom Penh and Vientiane, 2011.

[3] Bollaert, E., A comprehensive model to evaluate scour formation in plunge pools. International Journal on Hydropower and Dams, 2004(1), pp. 94101, 2004.

[4] Liu, P., A new method for calculating depth of scour pit caused by overflow water jets. Journal of Hydraulic Research, 43(6), pp. 695-701, 2005.

[5] Heng, S., Tingsanchali, T. and Suetsugi T., Analysis of plunge pool scour hole formation below a chute spillway with flip bucket using a physical model. ASEAN Engineering Journal, C1(1), pp. 88-101, 2012.

[6] Annandale, G.W., Scour technology, McGraw-Hill: New York, 2006.

[7] Yildiz, D. and Uzucek, E., Prediction of scour depth from free falling flip bucket jets. International Water Power and Dam Construction, 46(11), pp. 50-56, 1994.

[8] Mason, P.J. and Arumugam, K., Free jet scour below dams and flip buckets. Journal of Hydraulic Engineering, 111(2), pp. 220-235, 1985.

[9] Suppasri, A., Hydraulic performance of Nam Ngum 2 spillway, Asian Institute of Technology: Pathumthani, 2007.

[10] Mason, P.J., Effects of air entrainment on plunge pool scour. Journal of Hydraulic Engineering, 115(3), pp. 385-399, 1989.

[11] Hoffmans, G.J.C.M., Jet scour in equilibrium phase. Journal of Hydraulic Engineering, 124(4), pp. 430-437, 1998.

[12] Elevatorski, E.A., Hydraulic energy dissipators, McGraw-Hill: New York, 1959.

[13] Kawakami, K., A study on the computation of horizontal distance of jet issued from ski-jump spillway. Transaction of Japanese Society of Civil Engineers, 219(11), pp. 37-44, 1973.

[14] United States Bureau of Reclamation (USBR), Design of arch dams, USBR: Colorado, 1977.

[15] Taraimovich, I.I., Deformation of channels below high-head spillways on rock foundations. Journal of Power Technology and Engineering, 12(9), pp. 917-923. 1978.

[16] Moriasi, D.N., Arnold, J.G., Liew, M.W.V., Bingner, R.L., Harmel, R.D. and Veith, T.L., Model evaluation guidelines for systematic quantification of accuracy in watershed simulations. Transactions of the American Society of Agriculture and Biological Engineers, 50(3), pp. 885-900, 2007. 